University of South Carolina

Scholar Commons

$12-17-2010$

\title{
Effective Ionic Conductivity of a Novel Intermediate-Temperature Mixed Oxide-Ion and Carbonate-Ion Conductor
}

Xue Li

University of South Carolina - Columbia, lixue@cec.sc.edu

Guoliang Xiao

Kevin Huang

University of South Carolina - Columbia, huang46@cec.sc.edu

Follow this and additional works at: https://scholarcommons.sc.edu/emec_facpub

Part of the Mechanical Engineering Commons

\footnotetext{
Publication Info

Published in Journal of The Electrochemical Society, Volume 458, Issue 2, 2010, pages B225-B232.

(c)Journal of The Electrochemical Society 2010, The Electrochemical Society.

(C) The Electrochemical Society, 2010. All rights reserved. Except as provided under U.S. copyright law, this work may not be reproduced, resold, distributed, or modified without the express permission of The Electrochemical Society (ECS). The archival version of this work was published in Journal of The Electrochemical Society.

Publisher's Version: http://dx.doi.org/10.1149/1.3524477

Li, X., Xiao, G., \& Huang, K. (2010). Effective Ionic Conductivity of a Novel Intermediate-Temperature Mixed Oxide-Ion and Carbonate-Ion Conductor. Journal of The Electrochemical Society, 158 (2), B225 - B232. http://dx.doi.org/10.1149/1.3524477
}

This Article is brought to you by the Mechanical Engineering, Department of at Scholar Commons. It has been accepted for inclusion in Faculty Publications by an authorized administrator of Scholar Commons. For more information, please contact digres@mailbox.sc.edu. 


\title{
Effective Ionic Conductivity of a Novel Intermediate-Temperature Mixed Oxide-Ion and Carbonate-Ion Conductor
}

\author{
Xue Li, Guoliang Xiao, and Kevin Huang ${ }^{*, z}$ \\ Department of Mechanical Engineering, University of South Carolina, Columbia, South Carolina 29208, \\ USA
}

\begin{abstract}
A systematic investigation on the effective ionic conductivity $\left(\sigma_{\mathrm{m}}\right)$ of a novel intermediate-temperature mixed oxide-ion and carbonate-ion conductor (MOCC) consisting of a ceria phase and a carbonate phase is reported. The study explicitly shows that the observed remarkable temperature-dependent $\sigma_{\mathrm{m}}$ is primarily the result of softening/melting of the carbonate phase as the physical state of the carbonate phase transforms from solid, softened to molten. Differential scanning calorimetry analysis complements the understanding of the observed electrical behavior by revealing temperatures of melting and solidification in agreement with the onset temperatures of $\sigma_{\mathrm{m}}$. In addition, the measured $\sigma_{\mathrm{m}}$ agrees reasonably well with that simulated by the effective medium percolation theory. Furthermore, $\sigma_{\mathrm{m}}$ of the MOCC is independent of atmosphere at $t<600^{\circ} \mathrm{C}$, exhibiting the characteristics of a good electrolyte. The MOCC- $\mathrm{LiNiO}_{x}$ and MOCC-Ni composites are better cathode and anode materials than noble metals for MOCC-based fuel cells, respectively. Finally, no sign of $\sigma_{\mathrm{m}}$ degradation measured at $600^{\circ} \mathrm{C}$ in air is found over a 3-day period. C) 2010 The Electrochemical Society. [DOI: 10.1149/1.3524477] All rights reserved.
\end{abstract}

Manuscript submitted October 22, 2010; revised manuscript received November 11, 2010. Published December 17, 2010. This was Paper 1156 presented at the Las Vegas, Nevada, Meeting of the Society, October 10-15, 2010.

The discovery of new fast ionic conductors has been long pursued by solid state chemists due to the important roles they play in modern solid state ionic devices. The Sr- and $\mathrm{Mg}$-doped $\mathrm{LaGaO}_{3}$ (LSGM) perovskite oxide-ion conductor discovered in the mid1990 s is a good example illustrating the fruition of years' of continual efforts in this area. The oxide-ion conductivity of LSGM at $800^{\circ} \mathrm{C}$ is as high as that of $\mathrm{Y}_{2} \mathrm{O}_{3}$-doped $\mathrm{ZrO}_{2}$ at $1000^{\circ} \mathrm{C}$ and is stable over a broad range of partial pressures of oxygen. As an electrolyte of the solid oxide fuel cell (SOFC), these attributes connote higher chemical-to-electrical conversion efficiency (or less performance loss) at a given temperature and/or reduced operating temperature for a given performance. The latter is of practical importance because lowering the operating temperature of an SOFC could drastically improve the performance stability and reduce the system cost, the two foremost obstacles presently impeding the commercialization of the SOFC technology.

The common features of existing good oxide-ion conductors such as $\mathrm{ZrO}_{2^{-}}, \mathrm{CeO}_{2^{-}}$, and $\mathrm{LaGaO}_{3}$-based oxides can be characterized by oxygen vacancies available in the lattice and cubic structure of high symmetry. ${ }^{1-3}$ These two characteristics are known to facilitate fast oxide-ion conduction by creating an isotropic stress field within the lattice with a lowered motional enthalpy for oxygen vacancies. While fast oxide-ion conduction has also been observed in noncubic and anisotropic oxides such as $\mathrm{La}_{2} \mathrm{NiO}_{4+\delta}$, ${ }_{4-8}$ $\mathrm{GdBaCo}_{2} \mathrm{O}_{5+\delta},{ }^{9-12}$ and $\mathrm{CeNbO}_{4+\delta},{ }^{13}$ the involvement of mixedvalence transition metals prohibits these fast oxide-ion conductors from being good candidates for electrolytes due to a possible electronic conduction induced by the valence change in transition metals with surrounding atmospheres. The simultaneous requirements for mobile oxygen vacancies, high symmetry crystal structure, and fixed-valence cations (e.g., main-group elements) have severely limited finding new fast oxide-ion conductors among the available oxide systems.

An alternative class of materials that may have the potential to become good ionic conductors could be found in heterogeneous systems. The rationale behind this assertion is supported by the pioneering work of Liang, ${ }^{14}$ in which he demonstrated that the ionic conductivity of $\mathrm{Li}^{+}$can be markedly enhanced by well-dispersed, finegrained $\mathrm{Al}_{2} \mathrm{O}_{3}$ particles. Since then, a large number of multiphase systems have been investigated, ${ }^{15-30}$ particularly in the salt-oxide dual-phase systems including halide-oxide, ${ }^{15,16}$ oxyacid

* Electrochemical Society Active Member.

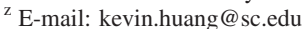

salt-oxide, ${ }^{17}$ and carbonate-oxide. ${ }^{18}$ Among these systems, the carbonate-oxide system has drawn particular attention in recent years due to its potential as an ion-transport material for fuel cells powered by fossil fuels and $\mathrm{CO}_{2}$ separation membranes.

The phenomenon of mixed oxide-ion and carbonate-ion conduction in a heterogeneous system is scientifically intriguing and technologically important. The microscopic features such as spacecharge distribution and point-defect concentration at the interfaces of the multiple phases have been reported to play significant roles in creating easy ionic pathways with exceptionally low motional enthalpy. ${ }^{19,20}$ A deeper insight into the coanion conduction mechanism in such a system will help identify other new heterogeneous fast ionic and/or electronic conductors for novel solid state ionic devices. From a practical viewpoint, a mixed oxide-ion and carbonate-ion conductor (MOCC) also finds applications in fuel cells powered by fossil fuels (including carbon) and the membrane in $\mathrm{CO}_{2}$ separation reactors. Because the dual-phase MOCC can be simply viewed as a combined electrolyte of those used in both SOFCs and molten carbonate fuel cells (MCFCs), a fuel cell based on the MOCC electrolyte can operate in the same manner as SOFCs and MCFCs without additional modifications in system designs and configurations. In addition, the solid oxide phase in an MOCC not only conducts oxide-ion but also immobilizes the molten carbonate phase. This feature mitigates the issues such as sealing and corrosions commonly encountered in MCFCs. Therefore, MOCC-based fuel cells are anticipated to last longer. In addition to using oxygen gas and $\mathrm{CO}_{2}$ as the oxidant, the advantage of fuel flexibility owned by conventional high temperature SOFCs and MCFCs can be naturally extended to the MOCC-based fuel cells. Recent studies have demonstrated an excellent electrical performance with a $250 \mu \mathrm{m}$ thick molten carbonate-ceria composite electrolyte in an SOFC configuration. ${ }^{21,22}$ The observed excellent performance has been postulated to result from enhanced oxide-ion conductivity as well as improved electrode kinetics by the presence of the molten carbonate phase.

Another potential application for the MOCC is as the membrane material for an electrochemical $\mathrm{CO}_{2}$ separation reactor. One immediate example of the application is the separation of $\mathrm{CO}_{2}$ from a mixture of $\mathrm{CO}_{2}$ and $\mathrm{H}_{2}$, the intermediate product of the water-gasshift reaction in commercial production of $\mathrm{H}_{2}$ from natural gas. With MOCC as the membrane, the corresponding electrochemical reactions occurring at the surfaces of membrane can be expressed as 


$$
\mathrm{CO}_{2}+\mathrm{O}^{2-}=\mathrm{CO}_{3}^{2-}
$$

A high concentration of $\mathrm{CO}_{2}$ in a mixture with $\mathrm{H}_{2}$ will electrochemically react with $\mathrm{O}^{2-}$ to form $\mathrm{CO}_{3}^{2-}$ at the feed side; $\mathrm{CO}_{3}^{2-}$ is then transported to the permeate side under the concentration gradient of $\mathrm{CO}_{2}$, releasing $\mathrm{CO}_{2}$ for capture and $\mathrm{O}^{2-}$ for charge balance. Recent modeling and experimental studies have shown that a sufficiently high $\mathrm{CO}_{2}$ flux density can be achieved through such an MOCC membrane. ${ }^{23-25}$

Despite the scientific and technological interests and increased research activities in recent years, ${ }^{26-30}$ MOCC as electrolyte and membrane materials have not yet been systematically studied. A comprehensive understanding of the electrical properties is still lacking. The present paper is aimed at addressing these issues by systematically investigating the electrochemical properties of a carbonate-ceria dual-phase composite as an ion-transport material. The study is particularly focused on characterizing the effect of softening/melting the carbonate phase on grain and grain-boundary conductions, the effect of atmospheres on the effective ionic conductivity, the effect on resistance of electrode materials, and the long-term stability of conductivity. The measured effective ionic conductivity is also modeled with the effective medium percolation theory (EMPT).

\section{Experimental}

Preparation of MOCC. - The solid oxide phase in this study was a gadolinium-doped $\mathrm{CeO}_{2}, \mathrm{Ce}_{0.9} \mathrm{Gd}_{0.1} \mathrm{O}_{2-\delta}$ (denoted as GDC), and the molten carbonate phase was a binary eutectic mixture of $\mathrm{Li}_{2} \mathrm{CO}_{3}$ and $\mathrm{K}_{2} \mathrm{CO}_{3}$ in a molar ratio of $62: 38$ (denoted as $\mathrm{MC}$ ). The GDC power was prepared using the glycine nitrate combustion method, ${ }^{31}$ followed by @ @ calcining at $600^{\circ} \mathrm{C}$ for $4 \mathrm{~h}$ to remove any trace of remaining organics. The binary eutectic salt $\mathrm{MC}$ was synthesized by solid state reaction between $\mathrm{Li}_{2} \mathrm{CO}_{3}$ and $\mathrm{K}_{2} \mathrm{CO}_{3}$ powers $\left(99.9 \%\right.$, Alfa Aesar) at $600^{\circ} \mathrm{C}$ for $2 \mathrm{~h}$. After cooling down to room temperature, the melt was then broken up and ball-milled with a high energy milling machine (McCrone Micronizing Mill, McCrone Microscopes, Westmont, IL). The obtained submicrometer MC powder was then intimately blended with GDC powder in ethanol in a predetermined volumetric ratio of 55:45 (MC/GDC), followed by calcining at $650^{\circ} \mathrm{C}$ for $2 \mathrm{~h}$ to ensure homogenization of MC with GDC particles. Thus, prereacted powder was ball-milled for the second time and uniaxially pressed at $200 \mathrm{MPa}$ into pellets (13 $\mathrm{mm}$ in diameter and $2-5 \mathrm{~mm}$ in thickness). The MOCC pellets were finally sintered at $650{ }^{\circ} \mathrm{C}$ for $2 \mathrm{~h}$ and ready for subsequent electrochemical characterizations. The diameters of the pellets became $12.69 \pm 0.08 \mathrm{~mm}$ after sintering. All heat-treatments of the samples were carried out in open air.

Because the conductivities of solid and softened carbonate are needed for modeling purpose and are not available from the literature, measuring this conductivity has been planned in the present study. The sample preparation is described as follows. The $\mathrm{Li}_{2} \mathrm{CO}_{3}$ and $\mathrm{K}_{2} \mathrm{CO}_{3}$ mixture of eutectic composition was heated in air to $650^{\circ} \mathrm{C}$ at a ramp rate of $2^{\circ} \mathrm{C} / \mathrm{min}$. After holding for $2 \mathrm{~h}$, the melt was then quenched to room temperature. Figures $1 \mathrm{a}$ and $1 \mathrm{~b}$ show the molten and quenched carbonate. A small disk sample was then cut from the bulk for conductivity measurement.

Preparation of electrodes.- The electrode materials used in this study include $\mathrm{Ag}, \mathrm{Au}, \mathrm{MOCC}-\mathrm{LiNiO}_{x}$ composite (intended for cathode), and MOCC-Ni composite (intended for anode). The Ag and $\mathrm{Au}$ electrodes were prepared from commercial Ag paste (Heraeus, C8829) and $\mathrm{Au}$ paste (Heraeus, C5755A), whereas homemade MOCC-LiNiO $x$ (in volume ratio 1:1) and MOCC-NiO (in volume ratio $1: 1$ ) composites were prepared by mixing the individual powders with a commercial binder (Heraeus, V-006) in a weight ratio of 2:3. The $\mathrm{LiNiO}_{x}$ powder in the cathode makeup was synthesized in air by reacting $\mathrm{LiOH}$ with $\mathrm{NiO}$ at $700^{\circ} \mathrm{C}$ for $2 \mathrm{~h} .{ }^{32}$ An electrode was fabricated by painting the prepared paste on the two surfaces of an MOCC and firing in air at $650^{\circ} \mathrm{C}$ for $2 \mathrm{~h}$. The active area of the

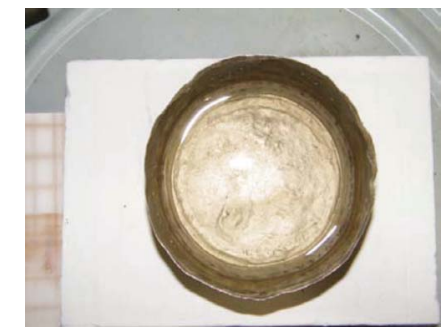

(a)

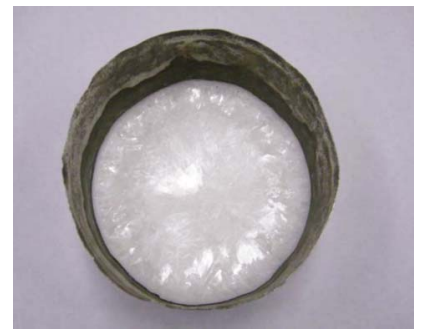

(b)
Figure 1. (Color online) Preparation of solid carbonate sample for conductivity measurement: (a) molten carbonate at $650^{\circ} \mathrm{C}$; (b) quenched carbonate.

samples was $1.27 \pm 0.02 \mathrm{~cm}^{2}$. NiO in the MOCC-NiO electrode is expected to become Ni during exposure to the $\mathrm{H}_{2}$-containing atmosphere. For carbonate only sample, only $\mathrm{Ag}$ is used as the electrode for measuring conductivity. For all electrodes investigated, Agmeshes along with Ag-leads served the current collectors.

Electrochemical characterizations.- All electrochemical measurements were performed with a symmetrical cell configuration using a Zahner IM6 Electrochemical Workstation (ZAHNERElectrik GmbH \& Co., Kronach, Germany). The symmetrical cell consisted of an MOCC or a carbonate and two identical electrode films. The temperature of interest varied from 400 to $650^{\circ} \mathrm{C}$ (to $489^{\circ} \mathrm{C}$ for carbonate only sample) in an interval of $5-25^{\circ} \mathrm{C}$ for both heating and cooling cycles. At each temperature, the cell was held for at least $30 \mathrm{~min}$ to ensure thermal and phase equilibria within the sample. The latter is particularly important for the measurements during the softening period of the carbonate phase. The atmospheres included air, $\mathrm{CO}_{2} / \mathrm{O}_{2}(1: 1)$, and $3 \% \mathrm{H}_{2} \mathrm{O}-\mathrm{H}_{2}$. The selection of atmospheres also depends on the type of electrodes studied. ac impedance spectroscopy was the primary experimental technique employed to characterize the electrical properties of the MOCC and carbonate. For each impedance measurement, the frequency was swept from $10 \mathrm{~Hz}$ (for bulk property study) or $10 \mathrm{mHz}$ (for electrode process study) to $8 \mathrm{MHz}$ (maximum) with an ac amplitude of $10 \mathrm{mV}$. The effective ionic conductivity of the MOCC was determined from the high frequency intersection of the spectrum with the $Z^{\prime}$ axis.

Other characterizations. - The melting behavior of the MOCC was investigated by differential scanning calorimetry (DSC) with a NETZSCH STA $409 \mathrm{C} / \mathrm{CD}$ thermal analysis system (Erich NETZSCH GmbH \& Co., Selb, Germany). The measurement was carried out in flowing air for both heating and cooling cycles at a ramp rate of $2^{\circ} \mathrm{C} / \mathrm{min}$. The microstructure of the MOCC was characterized with an FEI Quanta and XL 30 scanning electron microscope (SEM, North America NanoPort, Hillsboro, Oregon), while the local compositions of interest were particularly analyzed with the equipped energy-dispersive X-ray (EDX) analysis. To examine the chemical reactivity between GDC and MC, the powder X-ray diffraction was employed, the patterns of which were recorded on a MiniFlex ${ }^{\mathrm{TM}}$ II benchtop XRD system diffractometer (Rigaku, Rigaku Corporation, Tokyo, Japan) graphite-monochromatized $\mathrm{Cu}$ $\mathrm{K} \alpha$ radiation, $\lambda=1.5418 \AA$ ) from 20 to $80^{\circ}(2 \theta)$ with a scanning rate of $10 \% \mathrm{~min}$ and analyzed with JADE (MDI) software to identify any new phases if present.

\section{Results and Discussion}

XRD patterns and microstructure of the MOCC. - The XRD patterns of the MOCC after heat-treatment in air at $650^{\circ} \mathrm{C}$ for $2 \mathrm{~h}$ are shown in Fig. 2. Only the GDC phase is detectable, suggesting that no chemical reactions occurred between GDC and MC. The MC phase is not recognizable from the patterns due to its largely amorphous nature. A representative microstructure of the prepared two- 


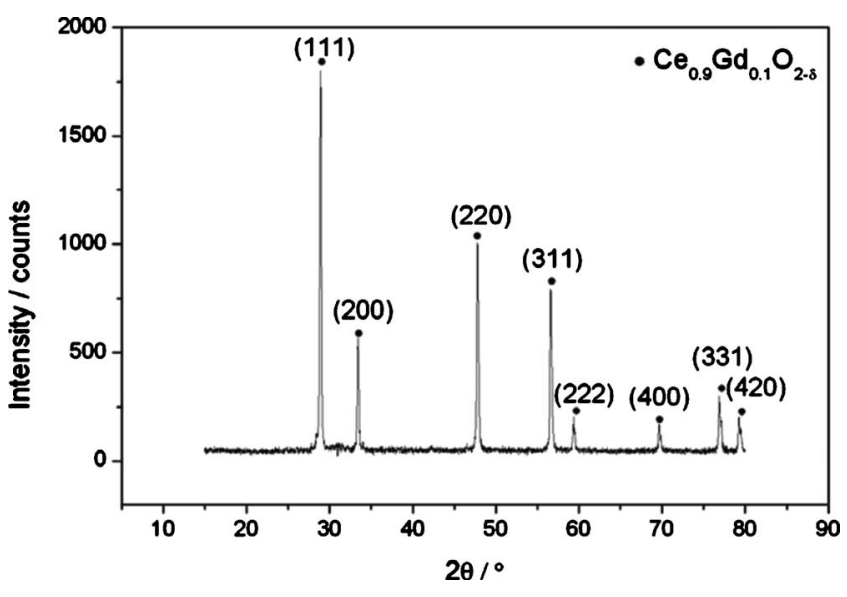

Figure 2. XRD patterns of an MOCC. The lattice reflection planes are labeled for GDC.

phase MOCC is shown in Fig. 3. No evidence for interconnected porosity is present. The EDX analysis indicates that the darker areas belong to the MC phase, whereas the lighter areas are the solid oxide phase. The two phases are randomly distributed across the sample. The formulation of the original phase composition also assures the percolation threshold for each phase. These are necessary conditions for using the EMPT approach to modeling the effective ionic conduction in a multiphase conductor. In Modeling the effective ionic conductivity with EMPT section, the results of effective ionic conductivity modeled with the EMPT will be given.

Effects of melting of the carbonate on impedance spectrum.- The ac impedance spectra measured on a Ag/MOCC/Ag symmetrical cell in air are shown in Fig. 4. The spectra display pronounced distinctions in three temperature regions: $t<460^{\circ} \mathrm{C}, 460^{\circ} \mathrm{C} \leqslant t$ $<490^{\circ} \mathrm{C}$, and $t \geqslant 490^{\circ} \mathrm{C}$. At $t<460^{\circ} \mathrm{C}$ (Fig. 4a), each spectrum depicts a defined semicircle at the high frequency and a possible embedded small semicircle at the intermediate frequency. While it is difficult to discern the individual contributions from the two phases involved, it is generally acceptable to ascribe these two semicircles to grain and grain-boundary contributions of the two phases. ${ }^{33}$ It is also known that the ceramic ceria phase is a dielectrically responsive material. ${ }^{34}$ In Ionic conductivity of solid and softened carbonate section, a similarly strong dielectric frequency response from the solid carbonate phase will also be shown. At $460^{\circ} \mathrm{C} \leqslant t<490^{\circ} \mathrm{C}$

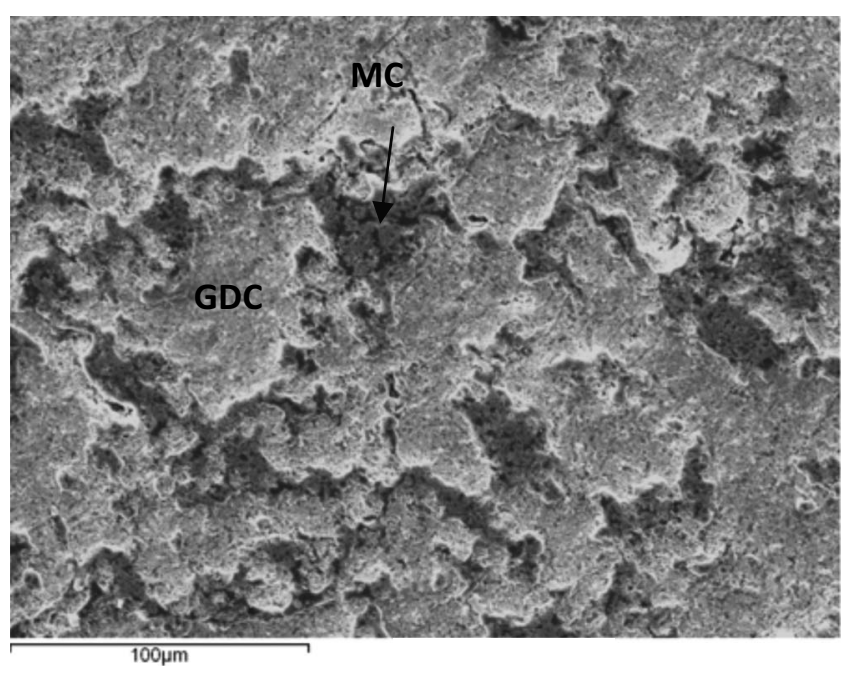

Figure 3. SEM image of the microstructure of an MOCC.
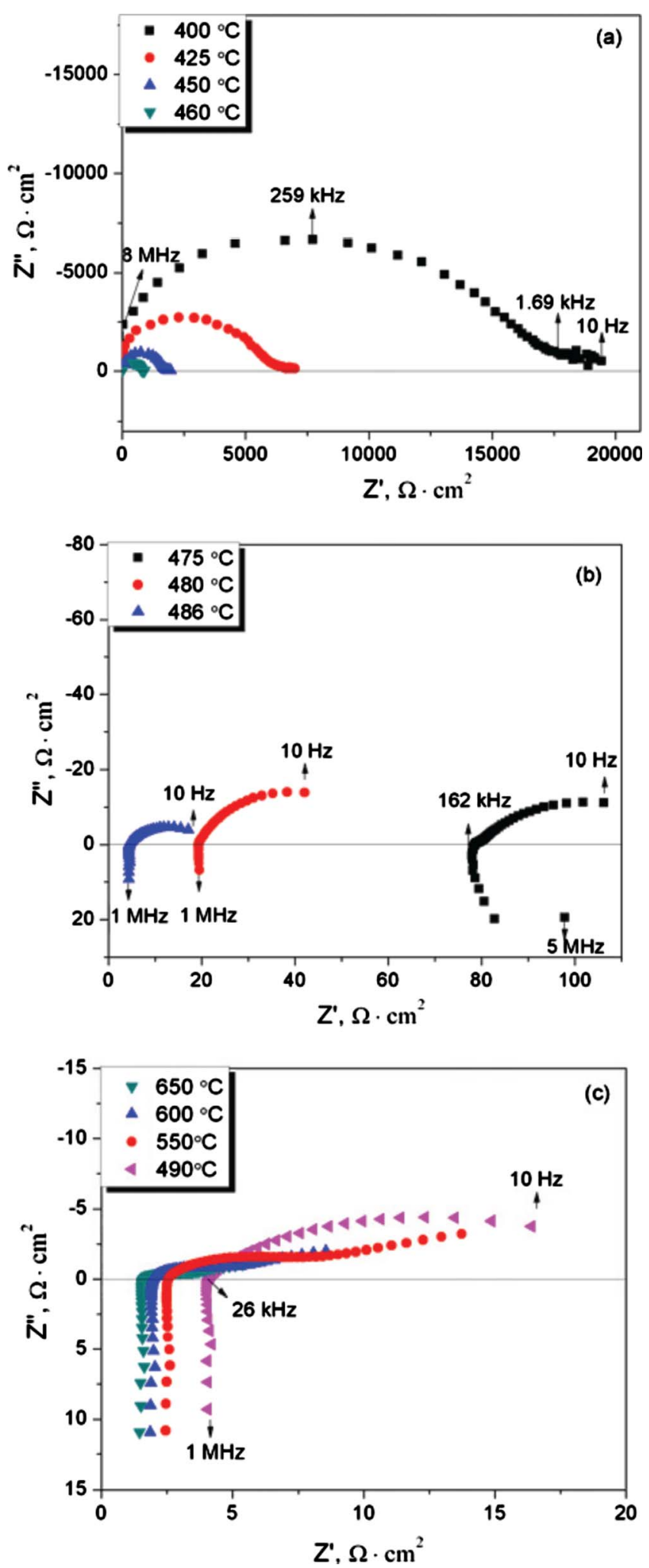

Figure 4. (Color online) ac impedance spectra of MOCC measured in air over a temperature range covering the melting point of the $\mathrm{MC}$ : (a) $t$ $<460{ }^{\circ} \mathrm{C}$; (b) $460{ }^{\circ} \mathrm{C} \leqslant t<490^{\circ} \mathrm{C}$; (c) $t \geqslant 490^{\circ} \mathrm{C}$.

(Fig. 4b), the spectra enter into a stage where the strong dielectric frequency response from the grains and grain-boundaries diminishes, accompanied by a rapid increase in the effective ionic conductivity $\left(\sigma_{\mathrm{m}}\right)$ with temperature. Based on the similarity in the melt- 


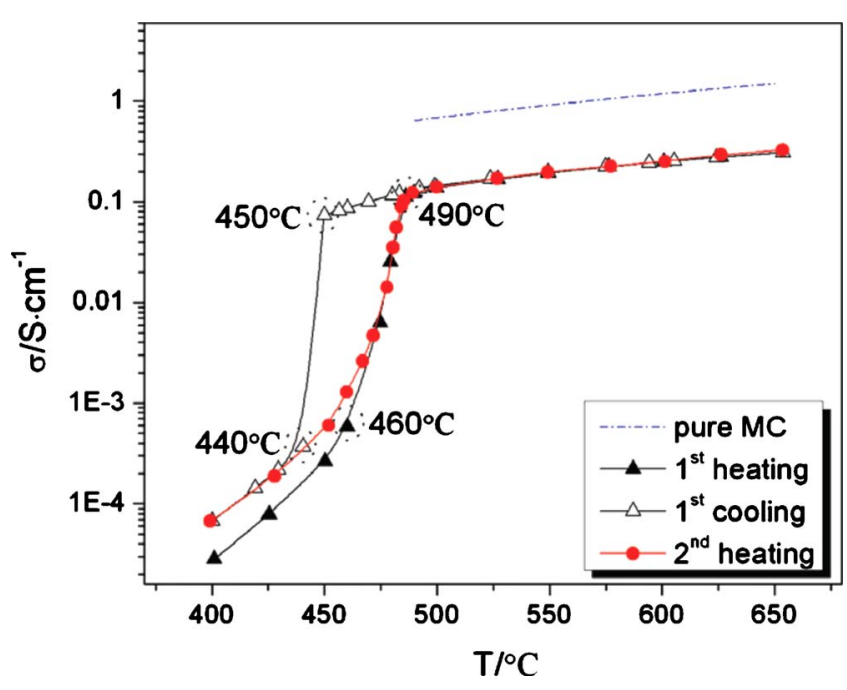

Figure 5. (Color online) Plot of the effective ionic conductivity of MOCC as a function of temperature.

ing behavior between MC and regular glasses, the observed behavior is most likely attributed to the softening of the MC phase prior to the ultimate melting. At $t \geqslant 490^{\circ} \mathrm{C}$, the grain and grainboundary semicircles completely vanish from the spectra (see Fig. 4c). The spectra are mainly dominated by the high frequency inductance impedance resulting from the measuring leads and the low frequency impedance of the electrode process. The disappearance of dielectric frequency response from the grains and grain-boundaries is clearly the result of an abrupt change in physical properties of the MOCC at $t \geqslant 490^{\circ} \mathrm{C}$. One obvious change is the melting of the carbonate phase. (This has been directly confirmed by the DSC analysis as will be discussed in the following.) The carbonate of the composition prepared for this study is known to melt at $\sim 490^{\circ} \mathrm{C}$, a temperature close enough to the observed spectrum or conductivityonset temperature. When the carbonate is in molten state, its conductivity is several orders of magnitude higher than that of solid carbonate as well as GDC. Under such a circumstance, the carbonate ions become the major charge carriers, whereas the oxide-ions become the minor ones. The grains and grain-boundaries associated with solid oxide phase no longer play a significant role in the impedance frequency response. The much lowered resistance and capacitance resulted from an increased conductivity and a lowered dielectric constant as the carbonate becomes a liquid phase. This situation will render the majority of the frequency domain to a more dominating inductance effect at the high frequency and electrode process at the low frequency, as shown in Fig. 4c.

Effect of melting of MC on the effective ionic conductivity.- The $\sigma_{\mathrm{m}}$ of the MOCC obtained from the high frequency intersection of the spectrum with the $Z^{\prime}$ axis is plotted in Fig. 5 as a function of temperature for one and half thermal cycles. Similar to Fig. 4, the $\sigma_{\mathrm{m}}$ also exhibits three distinct changes with temperature at $t$ $<460^{\circ} \mathrm{C}, 460^{\circ} \mathrm{C} \leqslant t<490^{\circ} \mathrm{C}$, and $t \geqslant 490^{\circ} \mathrm{C}$ during heating. The higher activation energy observed at $t<460^{\circ} \mathrm{C}$ is a clear indication of the grain and grain-boundary contributions in solid state MOCC. When the MC in the MOCC becomes softened in the range $460^{\circ} \mathrm{C} \leqslant t<490^{\circ} \mathrm{C}$, the $\sigma_{\mathrm{m}}$ experiences the strongest dependence on temperature. The $\sigma_{\mathrm{m}}$ is changed by 2 orders of magnitude within a $30^{\circ} \mathrm{C}$ temperature window. At $t \geqslant 490^{\circ} \mathrm{C}$, the MC completely melts; the conductivity becomes less dependent on temperature and follows a trend very similar to that of the pure MC phase, as indicated by the dotted line in Fig. 5. The similarity in activation energy evidently suggests that carbonate-ions are the dominant charge carriers in the MOCC at $t \geqslant 490^{\circ} \mathrm{C}$. In the same temperature regime at $t \geqslant 490^{\circ} \mathrm{C}$, the conductivity upon cooling is essentially the same as

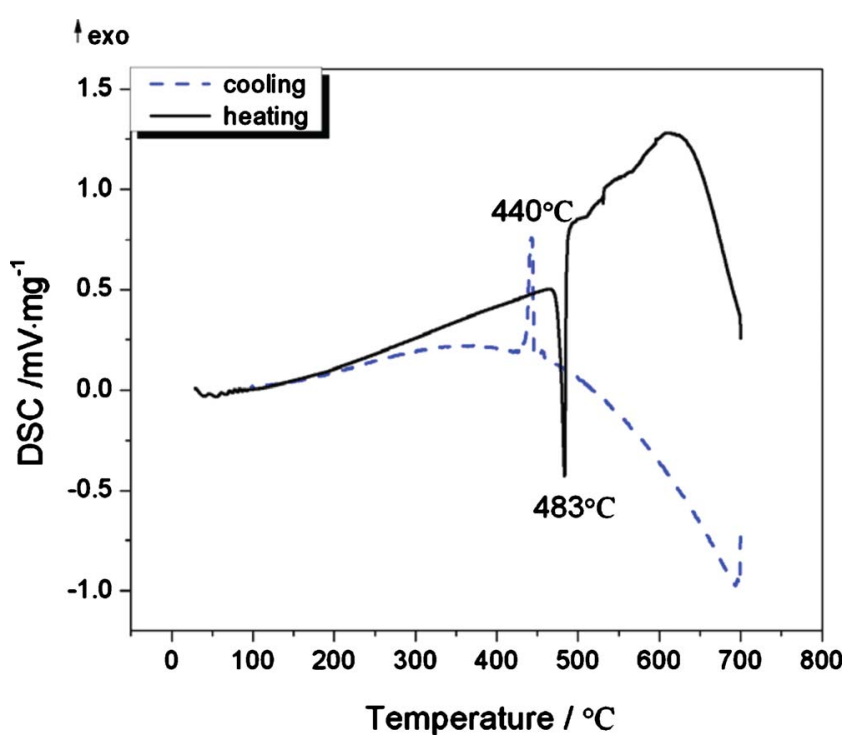

Figure 6. (Color online) DSC curves of an MOCC sample measured in flowing air.

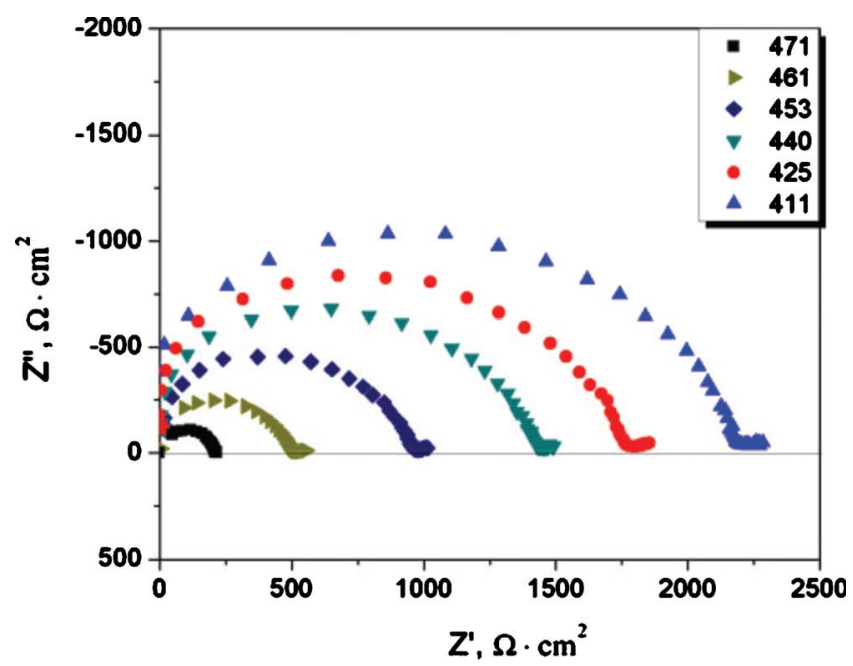

(a)

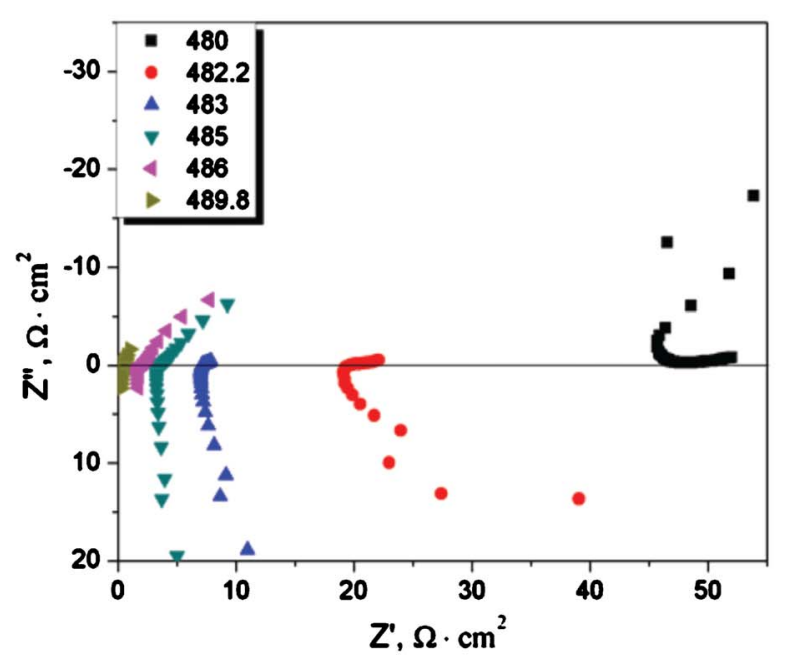

(b)

Figure 7. (Color online) ac impedance spectra of a solid (a) and softened (b) carbonate measured in air at different temperatures. 
that measured upon heating. However, this trend of higher conductivity and lower activation energy is retained to a temperature lower than $490^{\circ} \mathrm{C}$, e.g., $450^{\circ} \mathrm{C}$, after which a rapid decrease in conductivity from 450 to $440^{\circ} \mathrm{C}$ is observed. At $t<440^{\circ} \mathrm{C}$, the $\sigma_{\mathrm{m}}$ measured during cooling is higher than that measured upon heating, but with a similar temperature dependence. This higher $\sigma_{\mathrm{m}}$ is further retained during the second heating at $t \leqslant 475^{\circ} \mathrm{C}$, above which it is indistinguishable from that measured during the first heating cycle.

To better understand the conductivity hysteresis phenomenon, the melting behavior of the MOCC was analyzed by DSC and the result is shown in Fig. 6. Clearly, a thermal hysteresis is also observed in the melting/solidifying process of the MOCC. A strong endothermic peak is evident at around $483^{\circ} \mathrm{C}$ during the heating. This temperature not only matches well with the eutectic point of the MC phase $\left(490 \pm 5^{\circ} \mathrm{C}\right.$ for $\left.62 \mathrm{~mol} \% \mathrm{Li}_{2} \mathrm{CO}_{3}-\mathrm{K}_{2} \mathrm{CO}_{3}\right)$, suggesting its relevance to the melting of the carbonate phase, but also supports the conductivity dependence on temperature during heating, as shown in Fig. 5. However, the melt did not solidify until $440^{\circ} \mathrm{C}$ as shown by the exothermic peak measured during cooling. This delay of solidification to a lower temperature explains why the conductivity measured during the same cycle remains high to as low as $440^{\circ} \mathrm{C}$. The underlying mechanism of higher conductivity observed after $t<440^{\circ} \mathrm{C}$ in the cooling is unclear. A gradual sintering of solid oxide phase promoted by the presence of molten carbonate phase could account for the improved $\sigma_{\mathrm{m}}$ during the second heat cycle.

Ionic conductivity of solid and softened carbonate.- The ac impedance spectra of pure carbonate are shown in Fig. 7 for different temperatures. The evolution with temperature resembles that of MOCC shown in Fig. 4. At $t \leqslant 470^{\circ} \mathrm{C}$, the strong dielectric frequency response from the solid carbonate dominates the spectrum. At $t \geqslant 480^{\circ} \mathrm{C}$, when the carbonate phase becomes softened, the strong dielectric frequency response from grains vanishes with the spectra being replaced by the high frequency inductance and low frequency electrode process. The similarity between Fig. 4 and 7 further supports the assertion that the change in physical state of carbonate with temperature is the root cause of the observed spectrum evolution.

The temperature dependence of electrical conductivity of the carbonate is plotted in Fig. 8 where a drastic increase in conductivity is observed after $t>470^{\circ} \mathrm{C}$. This non-Arrhenius behavior is again very similar to what is shown in Fig. 5, further confirming that the unique conductivity behavior is indeed the result of physical state change of the carbonate phase.

Modeling the effective ionic conductivity with EMPT.- The EMPT is one of the most used models to theoretically describe the effective conductivity of a composite material. ${ }^{35-37}$ Random distribution of phases in the composite is the prerequisite of the theory. Each randomly distributed constituent phase is assumed to consist of small particles, the average size of which is much smaller than the dimensions of the samples so that the number of particles counted in any direction in the composite is reasonably large, but is much greater than the mean free path of charge carriers so that the nature of conduction in each particles and in each phase is similar to that in the corresponding bulk phase with large dimension.

For a multiphase composite system, the $\sigma_{\mathrm{m}}$ can be expressed as a function of volumetric fraction $V_{k}$ and total electrical conductivity $\sigma_{k}$ of phase $k^{37-39}$

$$
\sum_{k} \frac{\sigma_{\mathrm{m}}-\sigma_{k}}{(Z / 2-1) \sigma_{\mathrm{m}}+\sigma_{k}} V_{k}=0
$$

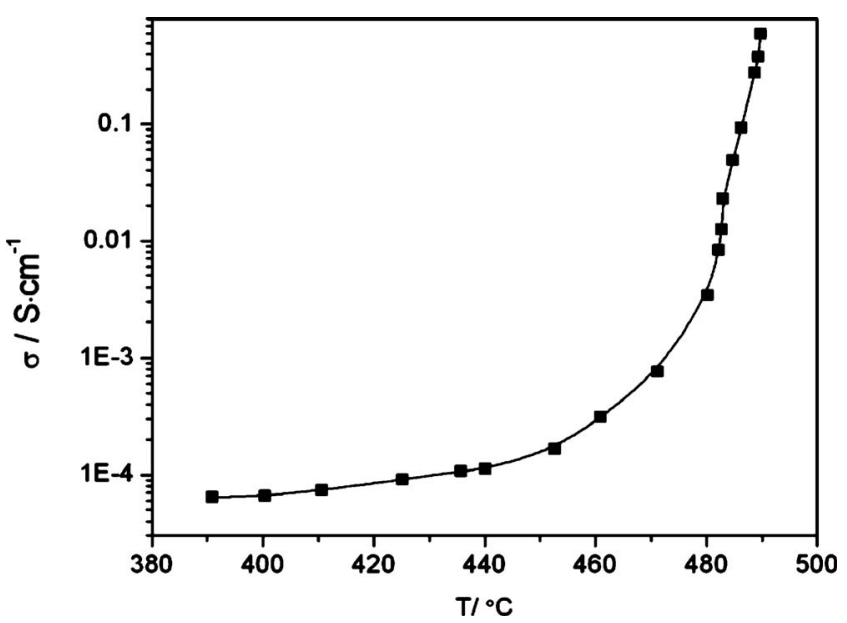

Figure 8. Electrical conductivity of carbonate as a function of temperature before melting.

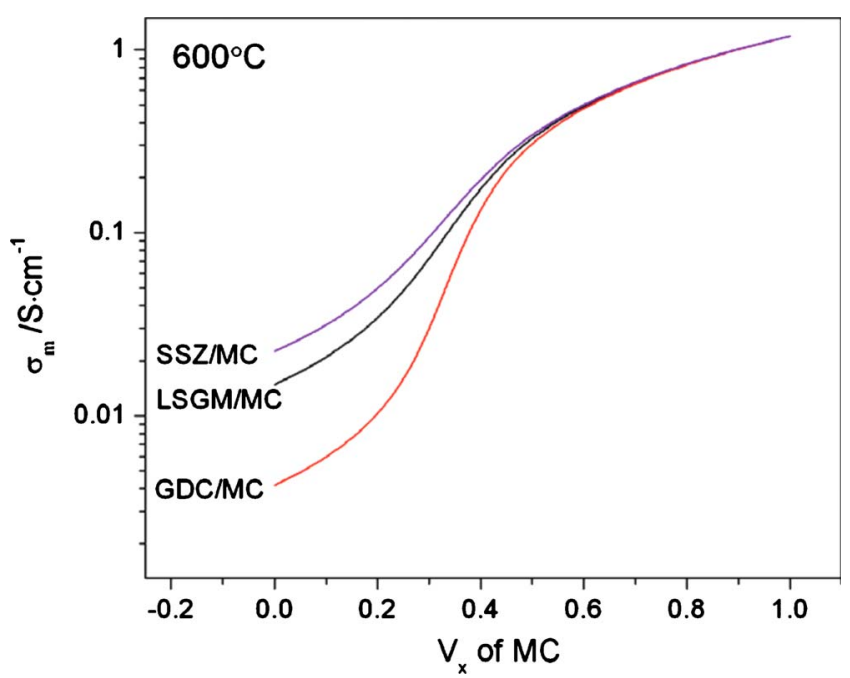

Figure 9. (Color online) Plot of effective ionic conductivity at $600^{\circ} \mathrm{C}$ of several solid oxide-carbonate systems as a function of volumetric fraction of the carbonate.

$$
\sum_{k} V_{k}=1
$$

For a two-phase composite, Eq. 1 can be further simplified into

$\sigma_{\mathrm{m}}$

$=\frac{3\left(V_{1} \sigma_{1}+V_{2} \sigma_{2}\right)-\left(\sigma_{1}+\sigma_{2}\right)+\sqrt{\left[3\left(V_{1} \sigma_{1}+V_{2} \sigma_{2}\right)-\left(\sigma_{1}+\sigma_{2}\right)\right]^{2}+8 \sigma_{1} \sigma_{2}}}{4}$ 
Table I. Parameters used in simulating effective ionic conductivity with the EMPT model.

\begin{tabular}{|c|c|c|c|}
\hline Electrolyte & Arrhenius equation & References & $\begin{array}{l}\text { Temperature } \\
\text { range }\left({ }^{\circ} \mathrm{C}\right)\end{array}$ \\
\hline $\mathrm{ScSZ}$ & $\ln \left(\sigma_{t} T\right)=-8482 / T+12.690$ & 38 & $400-650$ \\
\hline LSGM & $\ln \left(\sigma_{\mathrm{t}} T\right)=-12370 / T+16.730$ & 3 & $400-650$ \\
\hline GDC & $\ln \left(\sigma_{\mathrm{t}} T\right)=-12349 / T+15.434$ & 34 & $400-650$ \\
\hline $\mathrm{LiK}-\mathrm{MC}$ (molten) & $\operatorname{Ln}\left(\sigma_{t}\right)=-3716.7 / T+4.429$ & 39 & $490-650$ \\
\hline $\begin{array}{l}\mathrm{LiK}-\mathrm{MC} \text { (solid } \\
\text { and softened) }\end{array}$ & Measured data points & This study & $400-489$ \\
\hline
\end{tabular}

where $V_{1}$ and $V_{2}$ are the volumetric fractions of the solid oxide phase and carbonate phase, respectively; $\sigma_{1}$ and $\sigma_{2}$ are the total conductivities of the solid oxide phase and carbonate phase, respectively.

The calculated $\sigma_{\mathrm{m}}$ of MOCCs consisting of MC (LiK) and various solid oxides- $\mathrm{ScSZ}\left(10 \mathrm{~mol} \% \mathrm{Sc}_{2} \mathrm{O}_{3}-1 \mathrm{~mol} \% \mathrm{CeO}_{2}-\mathrm{ZrO}_{2}\right)$, LSGM $\left(\mathrm{La}_{0.8} \mathrm{Sr}_{0.2} \mathrm{Ga}_{0.83} \mathrm{Mg}_{0.17} \mathrm{O}_{3-\delta}\right)$, and GDC-is shown in Fig. 9 as a function of volumetric fraction of carbonate. The conductivity data used in simulation are listed in Table I. It is important to point out that the conductivities of different solid oxides listed in Table I represent the total $\sigma_{\mathrm{t}}$ (including grain and grain-boundary) but the grain $\sigma_{\mathrm{g}}$. It is necessary to use $\sigma_{\mathrm{t}}$ because the measured $\sigma_{\mathrm{m}}$ is the result of $\sigma_{\mathrm{t}}$, and not $\sigma_{\mathrm{g}}$, of the contributing phases. As expected, $\sigma_{\mathrm{m}}$ becomes completely dominated by the MC phase at $V_{\mathrm{MC}}>$ $\sim 67 \%$. No effect of solid oxide phase is visible. At lower $V_{\mathrm{MC}}$, e.g., $V_{\mathrm{MC}}<\sim 33 \%, \sigma_{\mathrm{m}}$ is more dictated by the solid oxide phase as evidenced by the curve separations among different solid oxides. The conductivity transition at the percolation threshold, e.g., 33\%, is not as pronounced as those observed in oxide-metal systems, ${ }^{37}$ primarily due to a lower $\sigma_{\mathrm{MC}} / \sigma_{\text {oxide }}$ than $\sigma_{\text {metal }} / \sigma_{\text {oxide }}$. The measured total conductivity of the $\mathrm{Li}-\mathrm{K}$ carbonate from this study is directly incorporated into the simulation (not in an analytical form due to a non-Arrhenius behavior during the MC softening period) to account for its share in conduction. Figure 10 shows the results comparing the simulated $\sigma_{\mathrm{m}}(\mathrm{GDC} / \mathrm{MC}=50: 50)$ with two measured ones ( $\mathrm{GDC} / \mathrm{MC}=45: 55)$ as a function of temperature. The simulated values are evidently in excellent agreement with those measured at $t>475^{\circ} \mathrm{C}$, where the carbonate is either in softened or in molten state. The fact that the measured $\sigma_{\mathrm{m}}$ of $\mathrm{GDC} / \mathrm{MC}=45: 55$ matches well with the simulated one of GDC/MC $=50: 50$ implies that an $\sim 6 \mathrm{wt} \%$ loss of $\mathrm{MC}$ occurred during fabrication process. At $t$ $\leqslant 450^{\circ} \mathrm{C}$, a general concurrence can also be reached between the

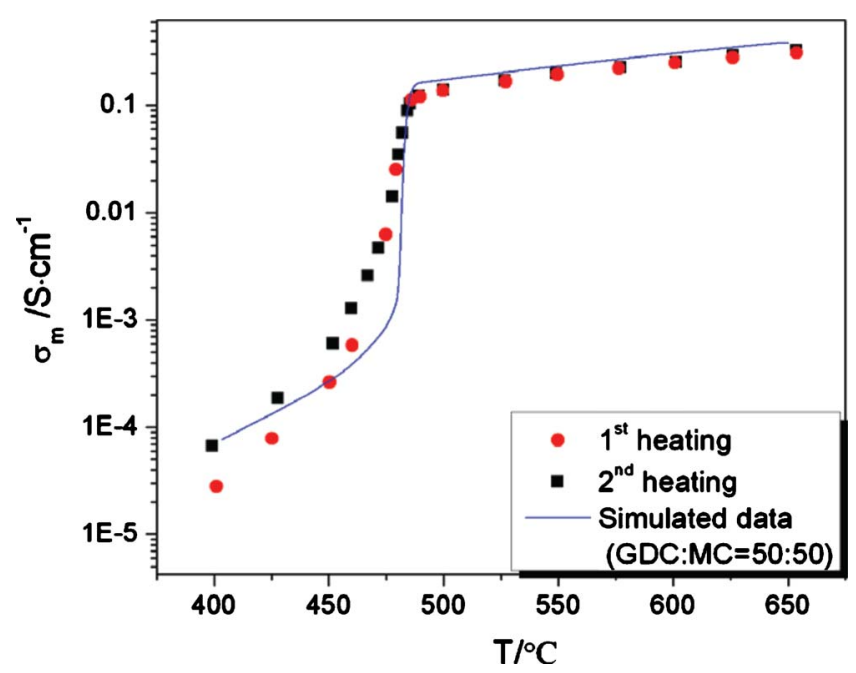

Figure 10. (Color online) Comparison of the simulated and measured effective ionic conductivities as a function of temperature. two except that the former has a lower activation energy than the latter. Recall that the GDC sample from which the total conductivity was measured and listed in Table I was sintered at $1585^{\circ} \mathrm{C},{ }^{34}$ whereas the GDC in the studied MOCC only sintered at $650^{\circ} \mathrm{C}$. More grain-boundary contributions are, therefore, expected from a low temperature sintered GDC sample, which may result in a higher activation energy and a lower overall conductivity. The apparent deviation between the simulated and measured values shown in Fig. 10 is in the temperature range of $450^{\circ} \mathrm{C}<t \leqslant 475^{\circ} \mathrm{C}$, where a drastic change of conductivity occurs. The thermal equilibrium during each measurement could play a role in the observed difference.

Effect of atmospheres on the effective ionic conductivity.- The ionic conductivity of a good electrolyte should be independent of partial pressure of the active species in the surrounding atmospheres. Therefore, examining this dependence is a necessary step in verifying whether a material is suitable for an electrolyte. In this study, three atmospheres covering a wide range of $P_{\mathrm{O}_{2}}$ and $P_{\mathrm{CO}_{2}}$ were selected, namely $\mathrm{CO}_{2} / \mathrm{O}_{2}$ (1:1), air (containing $\sim 385 \mathrm{ppm} \mathrm{CO}_{2}$ ), and $3 \% \mathrm{H}_{2} \mathrm{O}-\mathrm{H}_{2}$ (containing negligible $\mathrm{CO}_{2}$ ). Figure 11 shows representative ac impedance spectra measured at 500,600 , and $650^{\circ} \mathrm{C}$ with $\mathrm{Ag}$ as the electrode. While the electrode-related arcs show a variety of shapes in different atmospheres, the $\sigma_{\mathrm{m}}$ is given by the spectrum's high frequency intersection with the $Z^{\prime}$ axis. At $t$ $\leqslant 600^{\circ} \mathrm{C}$, the measured $\sigma_{\mathrm{m}}$ is essentially independent of atmosphere. (Spectra showing constant ionic conductivity at lower temperatures are not shown in Fig. 11 due to the page limitation.) At $t=650^{\circ} \mathrm{C}$, the measured conductivity noticeably increases with decreasing partial pressure of oxygen, indicating a possible electronic conduction in the GDC phase. In order to avoid the electronic conduction, the operating temperature of the GDC/MC-based MOCC in solid state ionic devices should be kept below $600^{\circ} \mathrm{C}$.

Effect of electrodes. - It is well known that a given electrolyte system is preferentially more compatible with one electrode system than another in solid state ionic devices such as the SOFC. Therefore, investigation of the compatibility of electrode materials for the MOCC electrolyte in fuel cell applications is equally important. Figure 12 shows $600^{\circ} \mathrm{C}$-impedance spectra measured on electrodes of $\mathrm{Ag}, \mathrm{Au}, \mathrm{LiNiO}_{x}-\mathrm{MOCC}$ (cathode), and $\mathrm{Ni}-\mathrm{MOCC}$ (anode) in atmospheres of air, $\mathrm{CO}_{2}-\mathrm{O}_{2}(1: 1)$ and $3 \% \mathrm{H}_{2} \mathrm{O}-\mathrm{H}_{2}$. In oxidizing atmospheres, air, and $\mathrm{CO}_{2}-\mathrm{O}_{2}, \mathrm{LiNiO}_{x}-\mathrm{MOCC}$ yields the lowest electrode resistance whereas in reducing atmosphere, i.e., $3 \% \mathrm{H}_{2} \mathrm{O}-\mathrm{H}_{2}$, $\mathrm{Ni}-\mathrm{MOCC}$ gives the lowest electrode resistance. In any case, $\mathrm{Au}$ is the worst electrode for both cathodic and anodic reactions. This finding indirectly confirms the fact that $\mathrm{Au}$ is always used as the inert counter electrode in electrochemical studies of MCFCs. Ag behaves mostly as a semiactive electrode in both oxidizing and reducing atmospheres. It is interesting to point out that the electrode resistances of $\mathrm{LiNiO}_{x}$ and $\mathrm{Ag}$ are both smaller in $\mathrm{CO}_{2}-\mathrm{O}_{2}$ than in air, implying the important role that carbonate ions play in the electrode kinetics.

Stability test of ionic conductivity.- The stability of ionic conductivity is another important characteristic of an electrolyte material used in any solid state ionic devices. Degradation of conductivity can cause deterioration of performance, shortening the lifetime of 

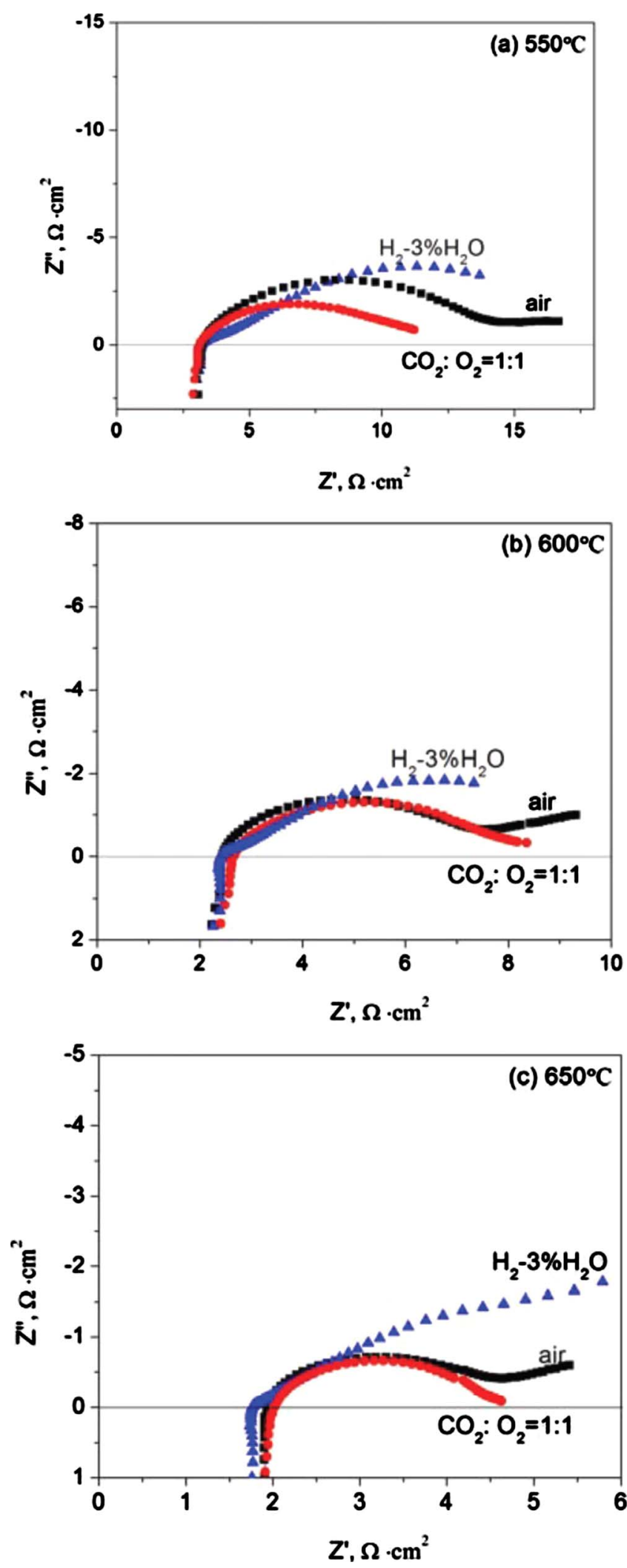

Figure 11. (Color online) ac impedance spectra of MOCC measured under different atmospheres and temperatures: (a) $550^{\circ} \mathrm{C}$; (b) $600^{\circ} \mathrm{C}$; (c) $650^{\circ} \mathrm{C}$.

devices. Figure 13 shows the $\sigma_{\mathrm{m}}$ measured at $600^{\circ} \mathrm{C}$ in air over a 3 -day period. No evidence of $\sigma_{\mathrm{m}}$ degradation is seen. Instead, $\sigma_{\mathrm{m}}$ is
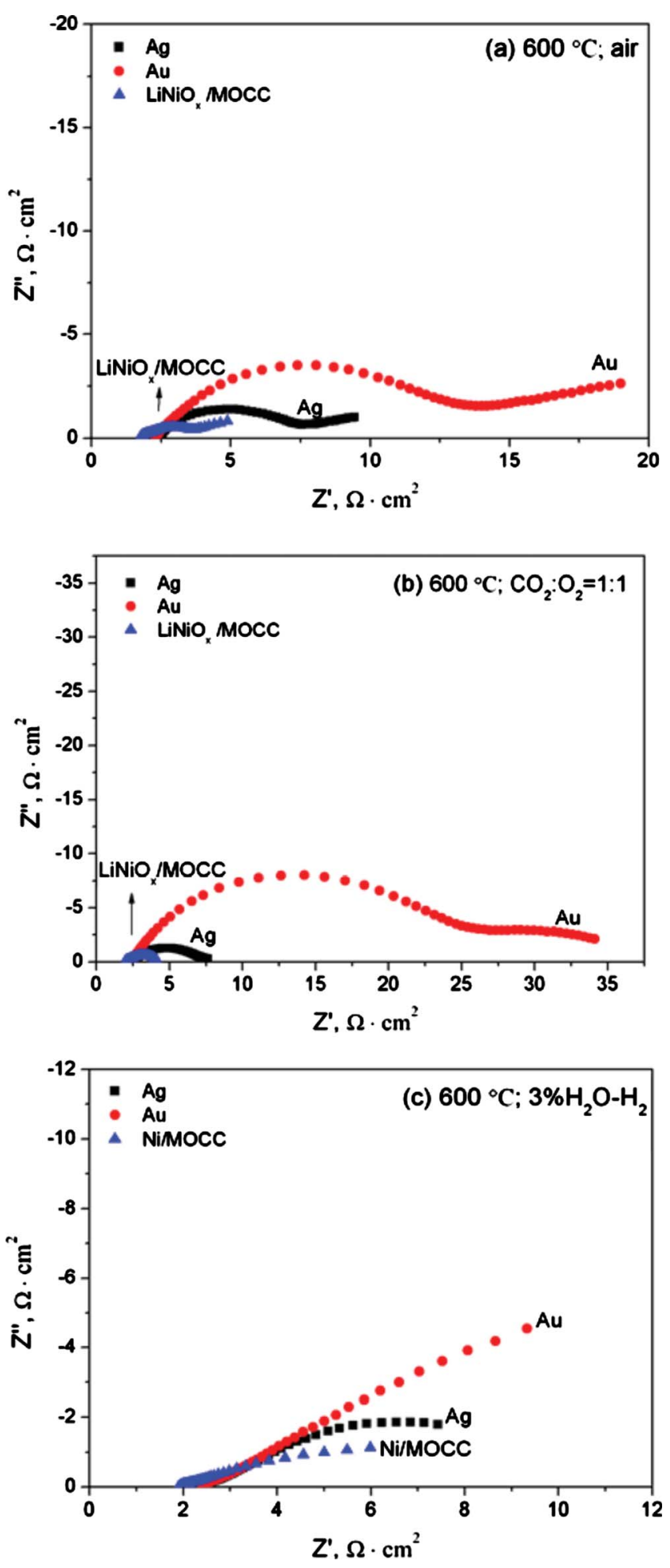

Figure 12. (Color online) ac impedance spectra of MOCC measured at $600^{\circ} \mathrm{C}$ with different electrodes and various atmospheres: (a) air; (b) $\mathrm{CO}_{2} / \mathrm{O}_{2}=1: 1 ;$ (c) $3 \% \mathrm{H}_{2} \mathrm{O}-\mathrm{H}_{2}$. The difference in ohmic resistance (high frequency intersection with $Z^{\prime}$ axis) is caused by different sample thickness.

improving with time during the measurement. Gradual sintering of GDC phase in the presence of molten carbonate could be the cause of the observed improvement.

\section{Conclusions}

The ac impedance spectra measured on the GDC/MC dual-phase MOCC exhibit a distinctive progression over an intermediate- 


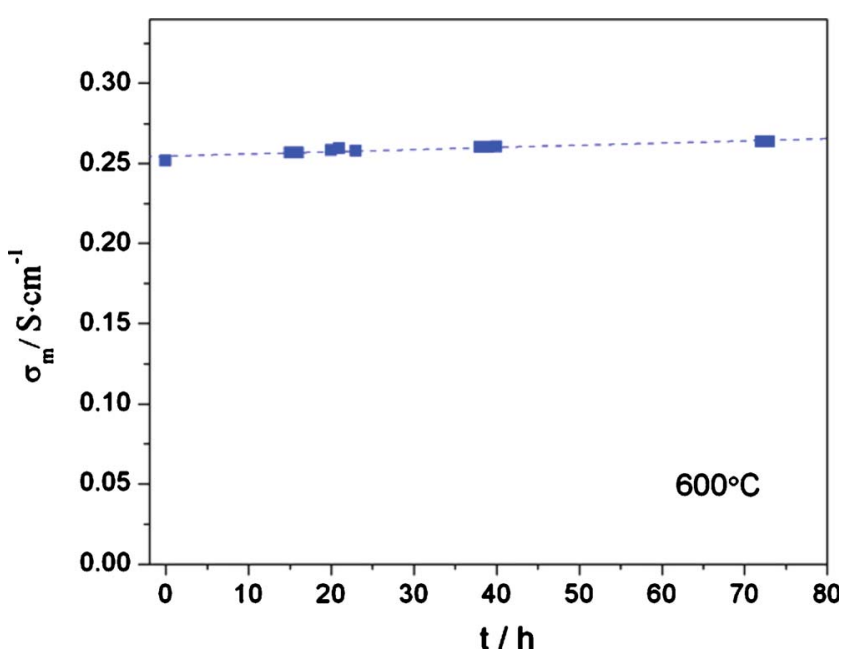

Figure 13. (Color online) Stability of $\sigma_{\mathrm{m}}$ measured at $600^{\circ} \mathrm{C}$ in air.

temperature range. At $t<460^{\circ} \mathrm{C}$, the spectra are mainly dominated by the dielectric responses from grains and grain-boundaries of the two solid phases. The $\sigma_{\mathrm{m}}$ is generally low with a high activation energy. At $460^{\circ} \mathrm{C} \leqslant t<490^{\circ} \mathrm{C}$, the spectra show diminishing grain and grain-boundary effects caused by the softening of the MC phase. The $\sigma_{\mathrm{m}}$ experiences a dramatic change: 2 orders of magnitude increase within a $30^{\circ} \mathrm{C}$ window. A $t \geqslant 490^{\circ} \mathrm{C}$, the contributions from grains and grain-boundaries completely vanish as a result of $\mathrm{MC}$ melting. The increased conductivity and decreased dielectric constant by the MC softening/melting considerably reduce the dielectric responses from the MOCC, allowing the inductance impedance resulting from the measuring leads and the electrode impedance to dominate at high and low frequency regimes, respectively. The $\sigma_{\mathrm{m}}$ follows a temperature dependence similar to that of the pure molten carbonate phase. The $\sigma_{\mathrm{m}}$ is also found to be different during heating and cooling, primarily at $t<490{ }^{\circ} \mathrm{C}$. This conductivity hysteresis behavior of the MOCC can be reasonably explained by the thermal hysteresis revealed by DSC analysis, in which the solidification temperature of the $\mathrm{MC}$ phase is $\sim 43^{\circ} \mathrm{C}$ lower on cooling than melting temperature on heating. The retained higher conductivity during cooling at $t<440{ }^{\circ} \mathrm{C}$ may imply a gradual sintering of the GDC phase in the presence of molten carbonate phase during measurement. The above explanations to the electrical behaviors of MOCC are further supported by the investigation of electrical properties of carbonate only sample.

Application of EMPT model to the studied MOCC system reveals an excellent agreement of the measured data with the simulated ones at $t>475^{\circ} \mathrm{C}$ when the carbonate phase is in either softened or molten state. At $t \leqslant 475^{\circ} \mathrm{C}$, the simulation results also concur reasonably well with the measured data except that the latter has a higher activation energy. This behavior is explained by the more contributions from grain-boundaries in the low temperature sintered sample than the high temperature sintered one, the conductivity of which was used for the simulation.

The $\sigma_{\mathrm{m}}$ retains its independence from different partial pressures of active species at $t \leqslant 600^{\circ} \mathrm{C}$, demonstrating the characteristics of a good electrolyte. At $t \geqslant 650^{\circ} \mathrm{C}$, the reduction of Ce introduces electronic conduction in the MOCC at low $P_{\mathrm{O}_{2}}$. In addition, the MOCC-LiNiO $x$ and MOCC-Ni composites are, respectively, better cathode and anode materials than $\mathrm{Ag}$ or Au for MOCC-based fuel cells. The $\sigma_{\mathrm{m}}$ measured at $600^{\circ} \mathrm{C}$ in air shows no sign of degradation but instead improves over time.

University of South Carolina assisted in meeting the publication costs of this article.

\section{References}

1. D. W. Strickler and W. G. Carlson, J. Am. Ceram. Soc., 48, 286 (1965).

2. B. C. H. Steele, Solid State Ionics, 129, 95 (2000).

3. K. Huang, R. Tichy, and J. B. Goodenough, J. Am. Ceram. Soc., 81, 2565 (1998)

4. M. Burriel, G. Garcia, J. Santiso, J. A. Kilner, J. C. C. Richard, and S. J. Skinner, J. Mater. Chem., 18, 416 (2008).

5. S. J. Skinner and J. A. Kilner, Solid State Ionics, 135, 709 (2000)

6. J. M. Bassat, P. Odier, A. Villesuzanne, C. Marin, and M. Pouchard, Solid State Ionics, 167, 341 (2004)

7. E. Boehm, J. M. Bassat, P. Dordor, F. Mauvy, J. C. Grenier, and P. Stevens, Solid State Ionics, 176, 2717 (2005).

8. M. Yashima, M. Enoki, T. Wakita, R. Ali, Y. Matsushita, F. Izumi, and T. Ishihara, J. Am. Chem. Soc., 130, 2762 (2008).

9. A. M. Chang, S. J. Skinner, and J. A. Kilner, Solid State Ionics, 177, 2009 (2006).

10. A. Tarancon, S. J. Skinner, R. J. Chater, F. Hernandez-Ramirez, and J. A. Kilner, J. Mater. Chem., 17, 3175 (2007).

11. A. Tarancon, A. Morata, G. Dezanneau, S. J. Skinner, J. A. Kilner, S. Estrade, F. Hernandez-Ramirez, F. Peiro, and J. R. Morante, J. Power Sources, 174, 255 (2007)

12. J. Pena-Martinez, A. Tarancon, D. Marrero-Lopez, J. C. Ruiz-Morales, and P. Nunez, Fuel Cells, 8, 351 (2008).

13. R. J. Packer and S. J. Skinner, Adv. Mater, 22, 1613 (2010).

14. C. C. Liang, J. Electrochem. Soc., 120, 1289 (1973).

15. Z. Zhao, C. Wang, S. Dai, and L. Chen, Solid State Ionics, 9/10, 1175 (1983)

16. J. B. Wagner, Jr., Mater. Res. Bull., 15, 1691 (1980).

17. B. Zhu and B. Mellander, J. Power Sources, 52, 289 (1994).

18. B. Zhu, X. Liu, P. Zhou, X. Yang, Z. Zhu, and W. Zhu, Electrochem. Commun., 3 , 566 (2001).

19. N. Sata, K. Eberman, K. Eberl, and J. Maier, Nature (London), 408, 946 (2000).

20. J. Garcia-Barriocanal, A. Rivera-Calzada, M. Varela, Z. Sefrioui, E. Iborra, C Leon, S. J. Pennycook, and J. Santamaria, Science, 321, 676 (2008).

21. C. Xia, Y. Li, Y. Tian, Q. Liu, Y. Zhao, L. Jia, and Y. Li, J. Power Sources, 188, 156 (2009).

22. C. Xia, Y. Li, Y. Tian, Q. Liu, Z. Wang, L. Jia, Y. Zhao, and Y. Li, J. Power Sources, 195, 3149 (2010).

23. Y. Li, Z. Rui, C. Xia, M. Anderson, and Y. S. Lin, Catal. Today, 148, 303 (2009).

24. J. L. Wade, K. S. Lackner, and A. C. West, Solid State Ionics, 178, 1530 (2007).

25. Z. Rui, M. Anderson, Y. S. Lin, and Y. Li, J. Membr. Sci., 345, 110 (2009).

26. J. Di, M. Chen, C. Wang, J. Zheng, L. Fan, and B. Zhu, J. Power Sources, 195, 4695 (2010).

27. W. Liu, Y. Liu, B. Li, T. Sparks, X. Wei, and W. Pan, Compos. Sci. Technol., 70, 181 (2010).

28. L. Zhang, R. Lan, X. Xu, S. Tao, Y. Jiang, and A. Kraft, J. Power Sources, 194, 967 (2009).

29. J. Huang, Z. Mao, L. Yang, and R. Peng, Electrochem. Solid-State Lett., 8, A437 (2005).

30. L. Jia, Y. Tian, Q. Liu, C. Xia, J. Yu, Z. Wang, Y. Zhao, and Y. Li, J. Power Sources, 195, 5581 (2010)

31. J. Y. Cho, S. H. Hyun, and S. A. Hong, J. Am. Ceram. Soc., 84, 937 (2001).

32. J. B. Huang, L. Z. Yang, R. F. Gao, Z. Q. Mao, and C. Wang, Electrochem. Commun., 8, 785 (2006)

33. E. Barsoukov and J. R. Macdonald, Impedance Spectroscopy: Theory, Experiment and Applications, p. 205, Wiley-Interscience, NJ (2005).

34. K. Huang and J. B. Goodenough, J. Am. Ceram. Soc., 81, 357 (1998).

35. S. Kirkpatrick, Rev. Mod. Phys., 45, 574 (1973).

36. D. S. McLachlan, J. Phys. C, 21, 1521 (1988).

37. Z. Wu and M. Liu, Solid State Ionics, 93, 65 (1997)

38. K. Huang and J. B. Goodenough, Solid Oxide Fuel Cell Technology: Principle, Performance and Operations, p. 224, Woodhead Publishing Co., Cambridge, UK (2009)

39. S. J. Chung, J. H. Park, D. Li, J.-I. Ida, I. Kumakiri, and J. Y. S. Lin, Ind. Eng. Chem. Res., 44, 7999 (2005) 